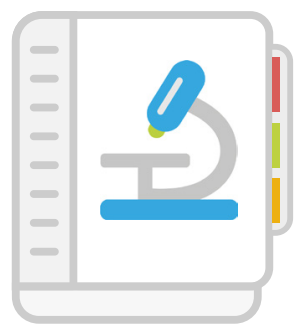

\title{
PRODUÇÃO DE MATERIAL DIDÁTICO PARA EDUCAÇÃO MEDIADA POR TECNOLOGIA APLICADA À SAÚDE
}

\author{
PRODUCTION OF DIDACTIC MATERIAL FOR EDUCATION MEDIATED BY
}

TECHNOLOGY APPLIED TO HEALTH

\begin{abstract}
Erivaldo da Silva Santos
Pedagogo. Acadêmico do Mestrado de Inovação em Tecnologias Educacionais (IMD - UFRN). Especialização em Ensino e Aprendizagem pela FACISA. Aperfeiçoamento em Mídias em Educação pela UERN.

Coordenador do Comitê Permanente de Desenvolvimento de Pessoas e Vice-coordenador do Núcleo de Educação Permanente do Hospital Universitário Onofre Lopes. E-mail: erivaldo.santos@ufrn.edu.br

Akynara Aglaé Rodrigues Santos da Silva Burlamaqui

Pedagoga. Doutora em Educação pelo Programa de Pós-graduação em Educação (UFRN). Mestre em Educação pelo Programa de Pós-graduação em Educação da UFRN. Professora Adjunta da Universidade Federal Rural do Semi-Árido (UFERSA). Professora do Programa de Pós-graduação em Inovação em Tecnologias Educacionais (IMD - UFRN). E-mail: akynara.aglae@ufersa.edu.br

\section{Aline de Pinho Dias}

Pedagoga. Doutora em Educação pela Universidade Federal do Rio Grande do Norte (UFRN). Mestre em Filosofia da Linguagem pela Universidade Federal do Ceará (UFC). Professora da Universidade Federal do Rio Grande do Norte. Pesquisadora do Laboratório de Inovação Tecnológica em Saúde (LAIS) e Membro do International Council for Open and Distance Education (ICDE). E-mail: alinepinhodias@gmail.com
\end{abstract}

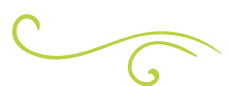

\section{RESUMO}

A formação de profissionais na área da saúde gera significativas transformações nos processos de trabalho e consequente impacto na qualidade dos serviços prestados. Pesquisadores do Laboratório de Inovação Tecnológica em Saúde (LAIS) desenvolveram o Ambiente Virtual de Aprendizagem do Sistema Único de Saúde (AVASUS) com a finalidade de aliar formação de qualidade e em larga escala aos profissionais do SUS. Nesse contexto, surge um grande desafio que é a preparação de profissionais para elaboração de conteúdo para educação mediada por tecnologia. Este estudo investiga as dificuldades enfrentadas por conteudistas do AVASUS no processo de elaboração dos módulos para a educação em saúde mediada por tecnologia, a fim de obter subsídios para futuras proposições pedagógicas relacionadas à formação desses conteudistas. A metodologia de pesquisa utilizada teve uma abordagem quali-qualitativa, a partir da aplicação de questionário de múltipla escolha, grupo focal e, finalmente, entrevistas individuais junto aos conteudistas com módulos finalizados, coordenadores de programa e servidores técnicos ligados ao processo de produção dos módulos. Assim, o levantamento realizado partiu de 
olhares diferentes, na perspectiva de identificação das necessidades operacionais e pedagógicas dos partícipes do processo, apurando resultados importantes, genuínos e inusitados. $O$ estudo evidenciou que $81 \%$ do público pesquisado nunca teve experiência na produção de material didático para Educação a Distância, em muitos casos, a maior dificuldade é escrever o material usando uma linguagem dialógica. Dessa maneira, propõe o desenvolvimento futuro de uma solução pedagógica eficaz para subsidiar os conteudistas, oferecendo-lhes mais aporte para produzir material didático com dialogicidade e qualidade.

Palavras-chave: Educação mediada por tecnologias. Educação permanente em saúde. Produção de material didático. Formação de conteudistas.

\section{ABSTRACT}

The training of professionals in the health area generates significant changes in the work processes and consequent impact on the quality of the services provided. Researchers at the Laboratory of Technological Innovation in Health (LAIS) developed the Virtual Learning Environment of the Unified Health System (AVASUS), with the purpose of allying quality and large-scale training to SUS professionals. In this context, a great challenge arises that is the preparation of professionals for the elaboration of content for education mediated by technology. This study investigates the difficulties faced by AVASUS content in the process of elaborating the modules for technologymediated health education in order to obtain subsidies for future pedagogical proposals related to the formation of these content. The research methodology used had a qualitative-qualitative approach, based on the application of multiple choice questionnaire, focus group and, finally, individual interviews with content managers with finished modules, program coordinators and technical servers linked to the production process of the modules. Thus, the survey was based on different perspectives, with a view to identifying the operational and pedagogical needs of the participants in the process, finding important, genuine and unusual results. The study evidenced that $81 \%$ of the surveyed public had never had experience in the production of didactic material for $E a D$, in many cases, the greatest difficulty is to write the material using a dialogic language. In this way, it proposes the future development of an effective pedagogical solution to subsidize the content, offering them more contribution to produce didactic material with dialogue and quality.

\section{Keywords:}

Technology-Mediated Education. Continuing Education in Health. Production of Didactic Material. Training of Accountants.

\section{INTRODUÇÃO}

A transformação dos processos de trabaIho gera impacto na qualidade dos serviços de saúde prestados à população, tornando-se indispensável a capacitação constante dos profissionais que atuam nessa área, fazendo com que novos conhecimentos e habilidades possam ser observados e aplicados à prática. Corroborando essa realidade, Oliveira et al. (2017, p. 161) afirmam que a formação dos profissionais de saúde deve ser "voltada para o desenvolvimento de competências que levem a uma atuação profissional diferenciada", que articulem aspectos fundamentais como promoção, prevenção e recuperação da saúde. Com isso, surge a necessidade de se realizar um trabalho coletivo e interdisciplinar, com mais atenção aos reflexos que a não ou a má formação profissional trazem para os serviços de saúde.

O Ministério da Saúde (MS), nos últimos anos, tem buscado novos princípios e modelos educacionais que promovam mudanças 
nas práticas dos serviços, fazendo com que a educação seja voltada às necessidades do trabalho. Por sua vez, as instituições têm exigido cada vez mais qualidade no trabalho prestado, oferecendo a seus colaboradores ações direcionadas ao desenvolvimento profissional permanente e contínuo, fortalecendo o desempenho de atividades alinhadas ao alcance de seus objetivos. Para isso, a oferta de possibilidades educacionais que fomentem efetivamente o desenvolvimento de competências para o exercício das atividades profissionais da saúde requer empenho dos envolvidos e aprimoramento dos métodos de ensino para que cheguem a todos, permitindo eficiência e eficácia na aplicação e nos resultados.

A Educação Permanente em Saúde (EPS) é uma estratégia de transformação de processos de trabalho e de práticas pedagógicas para a reorganização dos serviços de saúde, desenvolvendo capacidades a fim de resolver de maneira criativa os problemas que surgem nas rotinas das instituições. Estas, alinhadas às inovações tecnológicas, direcionam para o alcance de objetivos organizacionais, por meio de conceitos imediatamente aplicáveis ao cotidiano, gerando resultados satisfatórios, novos meios de aprendizagem e de inovação em saúde, bem como mudança na concepção e nas práticas cotidianas, visto que os colaboradores se tornam peças-chave no ensinar e no aprender. Como resultado, há a melhoria técnico-científica e a formação de profissionais críticos, éticos e engajados com o serviço, impactando diretamente em comportamentos, resultados e entregas. Nesse contexto, surge a importância da mediação tecnológica na formação humana em saúde, passando a desempenhar um papel primordial e expressivo no âmbito educacional e no desenvolvimento estratégico de profissionais e instituições de saúde.

Com o desenvolvimento da internet, os avanços das redes sociais e a difusão da educação a distância, muitas instituições e universidades atentaram para essas facilidades e passaram a utilizar-se de dispositivos móveis nos processos de ensino e aprendizagem (COSTA et al., 2018). Desse modo, a mediação tecnológica na formação humana vem contribuir com o desenvolvimento do pensamento crítico e reflexivo dos profissionais sobre suas realidades laborais, permeados pela interação e pelo fortalecimento da aprendizagem em um processo híbrido de construção e aplicação do conhecimento em seus cotidianos. Ademais, a educação mediada por tecnologia tem permitido mais flexibilidade no processo de ensino e aprendizagem diante do visível aumento das possibilidades no uso inovador de metodologias e recursos disponíveis, dotando o educando de autonomia para o desenvolvimento de competências fundamentais e técnicas.

\section{PRODUÇÃO DE MATERIAL DIDÁTICCO E DIALOGICIDADE NA EDUCAÇÃO MEDIADA POR TECNOLOGIA}

Os Ambientes Virtuais de Aprendizagem (AVAs) vêm proporcionando grandes impactos no paradigma educacional tradicional, trazendo mudanças na forma de ensinar e de aprender, provocando distintos modos de produção de conhecimento e de relacionamento interpessoal. A vista disso, pesquisadores do Laboratório de Inovação Tecnológica em Saúde (LAIS) desenvolveram o Ambiente Virtual de Aprendizagem do Sistema Único de Saúde (AVASUS) com a finalidade de aliar e ofertar formação de qualidade e em larga escala aos profissionais do Sistema Único de Saúde (SUS).

O material didático, disposto nos módulos do AVASUS, é produzido por profissionais detentores de relevante conhecimento e atuantes em determinada área da saúde, sendo em sua maioria professores, médicos e enfermeiros de diversas especialidades. Para ser um conteudista do AVASUS, o profissional precisa submeter-se a um processo 
seletivo. Após ser selecionado, deve participar de uma capacitação presencial e, em seguida, iniciar a produção do material didático proposto, ou seja, o desenvolvimento do conteúdo técnico específico. Esse processo de produção pode ser mais bem visto na Figura 1, em que consta fluxograma construído usando a Bizagi Modeler, uma ferramenta gratuita que possibilita a criação não só de fluxogramas como também de mapas mentais e diagramas em geral, organizando graficamente todo o processo e as relações existentes em cada etapa. Nesse fluxograma, usamos ainda a Business Process Model and Notation (BPMN), uma notação da metodologia de gerenciamento de processos de negócios, de padrão aberto mantida e disponibilizada pela Object Management Group (OMG), destacando-se por ter padrões de desenhos que facilitam o entendimento do usuário (OMG, 2011).

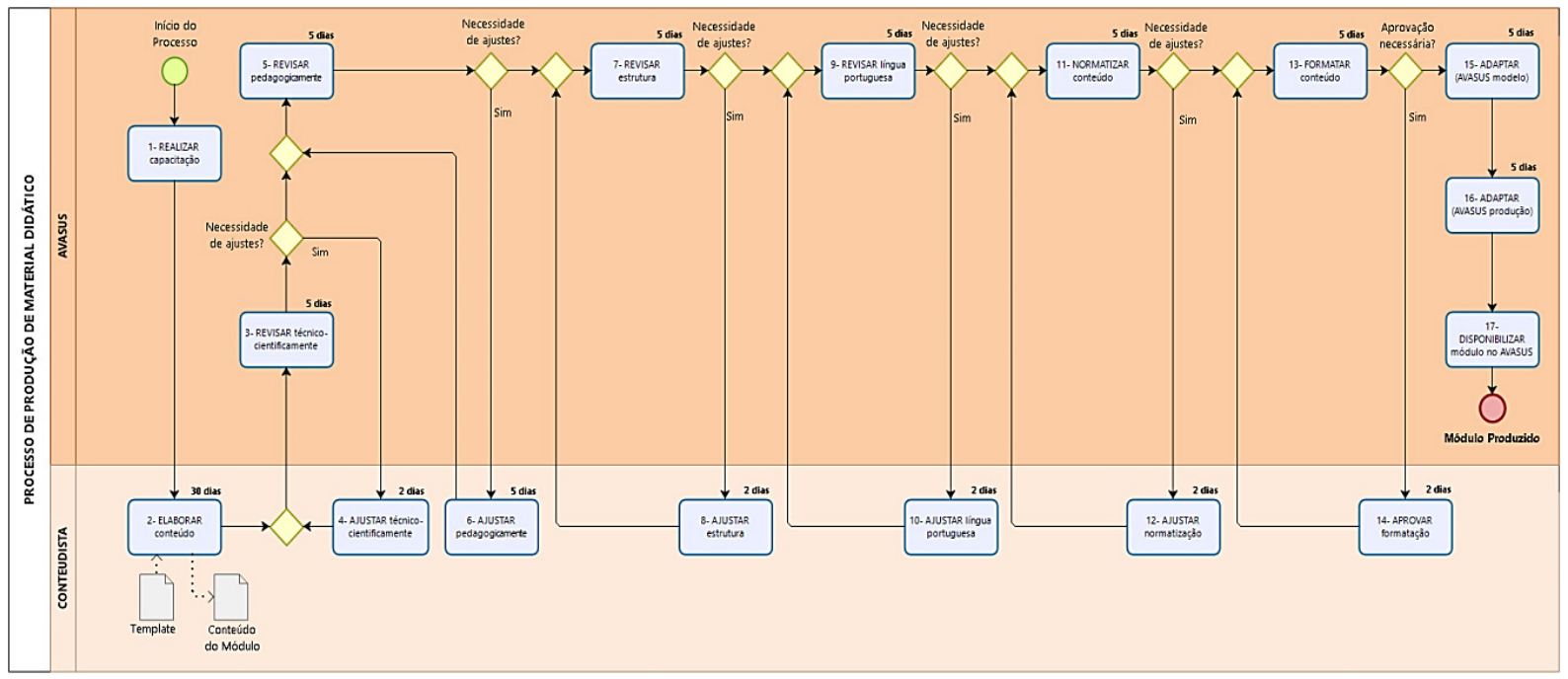

Figura 1 - Visão geral do processo de produção de material didático no AVASUS.

Fonte: Autoria própria (2019).

O AVASUS tem uma coordenação geral e coordenações de programas de produção de módulos, as quais enviam orientações aos conteudistas sobre o início do processo, que parte da capacitação presencial, abordando aspectos administrativos, técnicos e pedagógicos. Com esses conhecimentos básicos, os conteudistas iniciam a produção do material didático, seguindo determinado prazo para concluir o conteúdo, e enviam à revisão técnico-científica, que realiza os ajustes em conformidade com os preceitos da educação mediada por tecnologia e da própria especificidade do conteúdo. O material, após esse processo de revisão, pode ser ou não devolvido para o conteudista aprimorar a partir das modificações propostas. Nessa etapa, como também nas seguintes, o material didático escrito entra em filas de produção até ser disponibilizado ao aluno no AVASUS. Os prazos dispostos no fluxograma da Figura 1 podem variar de acordo com a natureza do material ou as demandas das equipes de produção.

Dando sequência, na revisão pedagógica, são examinados e ajustados aspectos pedagógicos gerais e específicos; na revisão de estrutura, são observadas e sugeridas alterações de aspectos relacionados à organização do conteúdo, recursos didáticos e gênero de linguagem; na revisão de língua portuguesa, são vistos aspectos linguístico-textuais; depois vem a etapa de normatização para revisão e adequações pertinentes à Associação Brasileira de Normas Técnicas (ABNT) e outras normas, quando necessário. 
A equipe de editoração realiza a diagramação do material, a produção de recursos didáticos como áudio, vídeos, figuras, infográficos, animações, jogos e outros meios educacionais previstos pelo conteudista no planejamento do módulo.

Ademais, a coordenação geral pode requerer assentimento do conteudista quanto à aprovação da formatação. Diante da concordância, a equipe de suporte inicia o decurso de adaptação à plataforma modelo do AVASUS, inserindo o conteúdo, revendo formatação dos recursos didáticos e eventuais carências, para então avançar na adaptação à plataforma de produção do AVASUS. Por fim, realiza-se a verificação final para que a coordenação geral possa liberar a disponibilização na internet.

O AVASUS tem se apresentado como potencial ferramenta para o desenvolvimento humano e a formação em saúde, no sentido de cooperar para a otimização da dinâmica do ensino e da aprendizagem, como também por proporcionar melhor aproveitamento dos conteúdos e a valorização da relação teoria e prática. Com isso, surge um grande desafio que é a preparação de profissionais para elaboração de material didático para educação mediada por tecnologia, uma vez que o material a ser elaborado é instrumento para o diálogo permanente entre alunos, professores e conteúdo, necessitando estar integrado a pressupostos pedagógicos e à dinâmica da respectiva plataforma de ensino.

À vista disso e partindo da concepção freiriana da aprendizagem, destacamos quatro elementos fundamentais à produção de material didático para educação mediada por tecnologia: a problematização, a conscientização, a contextualização e a dialogicidade. Nesse processo, o aluno aprende significativamente quando a motivação parte da problematização de situações reais do seu cotidiano, permitindo a compreensão crítica da realidade em que se vive, por meio da conscientização e consequente mudança desse meio (FREIRE,
2010). Com base nos conhecimentos prévios dos alunos, é possível construir uma aprendizagem contextualizada, tendo na dialogicidade um dos principais pressupostos para uma proposta pedagógica crítica.

Nessa mesma perspectiva de educação mediada por tecnologia, Laaser (1997) informa que os elaboradores (conteudistas) devem escrever de modo a conversar constantemente com o aluno, promovendo um diálogo amigável e encorajador, servindo de fio condutor, reforço e incentivo no desenvolvimento das atividades. Filatro (2008) reforça que desenvolver a conversa instrucional, usando ou não agentes pedagógicos para estabelecer um elo de proximidade com o aluno é uma das tarefas mais importantes nesse tipo de solução educacional. Portanto, na educação mediada por tecnologia, a aprendizagem está diretamente ligada à interação do aluno com o conteúdo e deve ocorre continuamente, sendo de fundamental importância o modo dialógico como o material didático é produzido e disponibilizado para o educando.

Segundo Freire (2010), é na realidade mediatizadora que buscaremos o conteúdo programático e o diálogo como prática da liberdade na educação. O diálogo começa antes da ação pedagógica em si. Ele surge na investigação temática, na pesquisa dos conteúdos programáticos e dele nascem temas geradores e componentes desse conteúdo. É no diálogo que ocorrem o entendimento e a maneira de concretização da dialogicidade, desse modo, um conteúdo interativo deve conversar com o aluno. Ainda de acordo com Freire (2010), o diálogo não começa no primeiro encontro entre educandos e educadores, mas logo na definição do conteúdo programático, a partir da escolha dos aspectos que estabelecerão o diálogo entre ambos.

Não obstante, percebeu-se que, de forma geral, os profissionais da saúde não têm formação pedagógica nem competências desenvolvidas para a elaboração de material didático na conjuntura da educação 
mediada por tecnologia, uma vez que essa é uma prática educacional que vem se transformando rápida e radicalmente nos últimos tempos. Vale destacar que a maior parte dos conteudistas estudados tem vasta experiência na educação presencial e pouca ou nenhuma experiência com educação mediada por tecnologias.
Nesse contexto, buscou-se compreender a importância da mediação tecnológica na formação humana e as dificuldades dos conteudistas no processo de produção de material didático para educação mediada por tecnologia aplicada à saúde, oferecendo aporte para futuras proposições pedagógicas que possam subsidiar os conteudistas na produção de material didático dialógico.

\section{PROCEDIMENTO METODOLÓGICO}

Este estudo foi realizado com 21 (vinte e um) conteudistas, 01 (um) coordenador de programa e 02 (dois) profissionais ligados ao AVASUS, entre janeiro e maio de 2018. Entre eles, estavam profissionais da saúde atuantes nas áreas médica, assistencial e administrativa. A Figura 2 mostra o perfil geral do público pesquisado, cujos dados apontam a predominância do sexo feminino, a maior parte com idade entre 36 e 45 anos e atuante na área assistencial. Ainda é possível perceber que $61,9 \%$ desses conteudistas têm pós-graduação stricto sensu em nível de mestrado e doutorado.

A escolha do público da pesquisa teve como critério principal estar ligado direta ou indiretamente ao processo de produção de material didático para educação mediada por tecnologia aplicada à saúde para o AVASUS. Optou-se por pesquisar distintos atores do processo, na perspectiva de apurar resultados reais e significativos para o estudo.

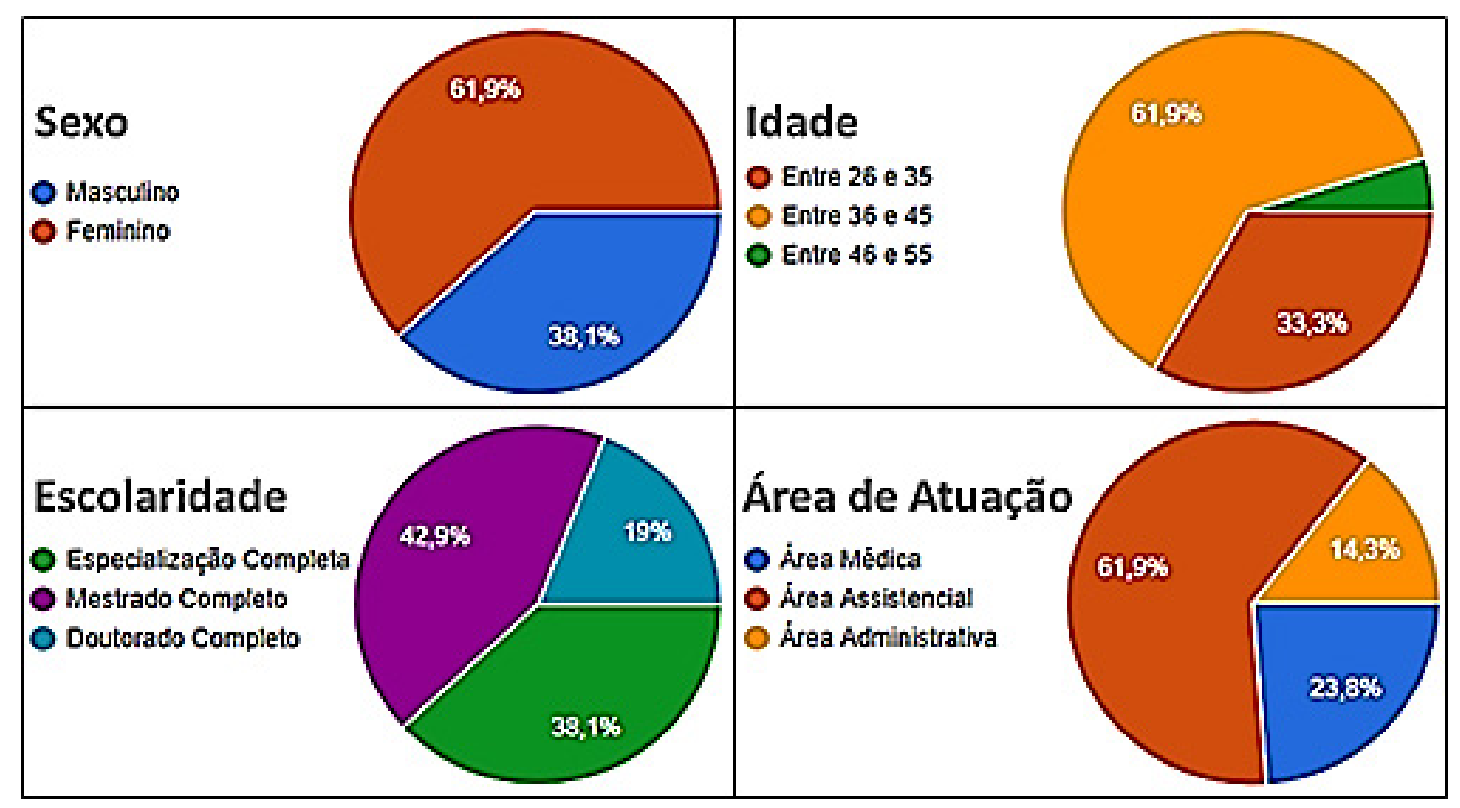

Figura 2 - Gráficos do perfil geral do público alvo. Fonte: Autoria própria (2018). 
A metodologia de pesquisa utilizada teve uma abordagem quali-qualitativa a partir da aplicação de questionário de múltipla escolha, grupo focal e, finalmente, entrevistas individuais com conteudistas que haviam finalizado os módulos, coordenadores de programas e servidores técnico-administrativos ligados ao processo de produção dos módulos. A pesquisa quali-quantitativa permitiu o cruzamento de conclusões como também mais confiança nos dados coletados e apresentados. Por se tratar de um método misto, favoreceu a aplicação simultânea dos métodos qualitativos e quantitativos, proporcionando um efeito transformador ao objeto de estudo (CRESWEL, 2007). De acordo com Giddens (2012), esse tipo de abordagem pode ser realizado pelo método misto, de modo a obter compreensão e explicação mais ampla sobre o tema estudado.

Para a abordagem quali-quantitativa, no primeiro momento, realizou-se questionário on-line (pesquisa survey). De acordo com Fonseca (2002, p. 33), a pesquisa survey busca a obtenção de dados ou informações sobre as características, as ações ou as opiniões de determinado grupo de pessoas, indicado como representante de uma população-alvo, utilizando um instrumento de pesquisa, usualmente um questionário. Em um segundo momento, usamos para coleta de informações o grupo focal, que, para Vergara (2004), é apropriado para o estudo que tem o objetivo de explicar como as pessoas consideram uma experiência, uma ideia ou um evento, tendo em vista que a discussão é efetiva no sentido de fornecer informações sobre o que as pessoas pensam, sentem, ou, ainda, sobre a forma como agem.

Por fim, realizaram-se entrevistas individuais abertas com o intuito de obter o maior número possível de informações. Segundo Minayo (1993), a entrevista aberta geralmente é utilizada a fim de descrever casos individuais na compreensão de especificidades culturais para determinados grupos e para comparabilidade de diversos casos. Dessa maneira, o levantamento realizado partiu de olhares diferentes, na perspectiva de identificação das necessidades operacionais e pedagógicas dos partícipes do processo, apurando resultados importantes, genuínos e inusitados.

\section{RESULTADOS E DISCUSSÕES}

As práticas educativas, influenciadas pelas tecnologias da informação e comunicação, no contexto da formação em saúde, vêm sofrendo influência dinâmica e contínua frente às novas maneiras de ensinar e de aprender em serviço. O sistema de saúde brasileiro e as políticas públicas para a formação de trabalhadores precisam responder às necessidades dos usuários dos serviços de saúde. Para isso, o SUS tem buscado iniciativas, como o Departamento de Informática do Sistema Único de Saúde (DATASUS), que participa dessa estratégia desenvolvendo e oferecendo conteúdo específico, provendo infraestrutura tecnológica e disponibilizando ambientes virtuais para trabalhos colaborativos e cursos relacionados com a área de saúde pública.

Nessa perspectiva, o SUS vem criando AVAs com conteúdo voltado para os profissionais da área de saúde, dos quais citamos - UniverSUS, programa do MS que se propõe a disponibilizar gratuitamente cursos a distância sobre informação e informática na saúde. O Sistema Universidade Aberta do SUS (UNA-SUS), outra iniciativa criada em 2010, visa atender as necessidades de capacitação e educação permanente de seus profissionais, oferecendo cursos abertos on-line de extensão, aperfeiçoamento, especialização e até mestrados profissionais, abordando desde assuntos específicos como diagnóstico e tratamento de doenças até temáticas mais abrangentes, como políticas públicas em saúde.

O lócus deste estudo é o AVASUS, plataforma que tem como objetivo democratizar 
a formação em saúde, qualificando a gestão e a assistência no SUS, por meio da oferta de cursos produzidos por instituições de ensino de todo o país, com referência em educação a distância, promovendo o conhecimento integrado e acessível. O AVASUS está na Versão 2.0, com um total de 284.481 usuários cadastrados, 570.042 matrículas realizadas, 149 cursos ativos, 5 inativos e 258.024 usuários aptos à certificação (AVASUS, 2018). Esses dados vêm introduzir nossa discussão, mostrando que os números são significativos, possibilitando compreender mais o ambiente de estudo e os fatores que envolvem o processo de produção de material didático. Na Figura 3, temos um gráfico com a visão geral do número de usuários cadastrados por curso.
Os cursos são produzidos a partir das necessidades e da demanda que o SUS apresenta, elaborados na perspectiva de qualificar a formação em saúde, dando possibilidade ao profissional de acessar o conteúdo a qualquer hora e em qualquer lugar, respeitando a rotina e a disponibilidade do trabalhador de saúde. Os cursos (módulos) são autoinstrucionais, ou seja, o ensino e a aprendizagem acontecem entre o estudante e o AVA, na interação, no retorno imediato e no acompanhamento das atividades e do desempenho do estudante. Alinhando-se ao que diz Figueiredo et al. (2016), o curso autoinstrucional é uma modalidade a distância que vem ganhando destaque na área da saúde, disponibilizando um material autoexplicativo e de fácil aprendizado, por meio da interação apenas do aluno com o computador.

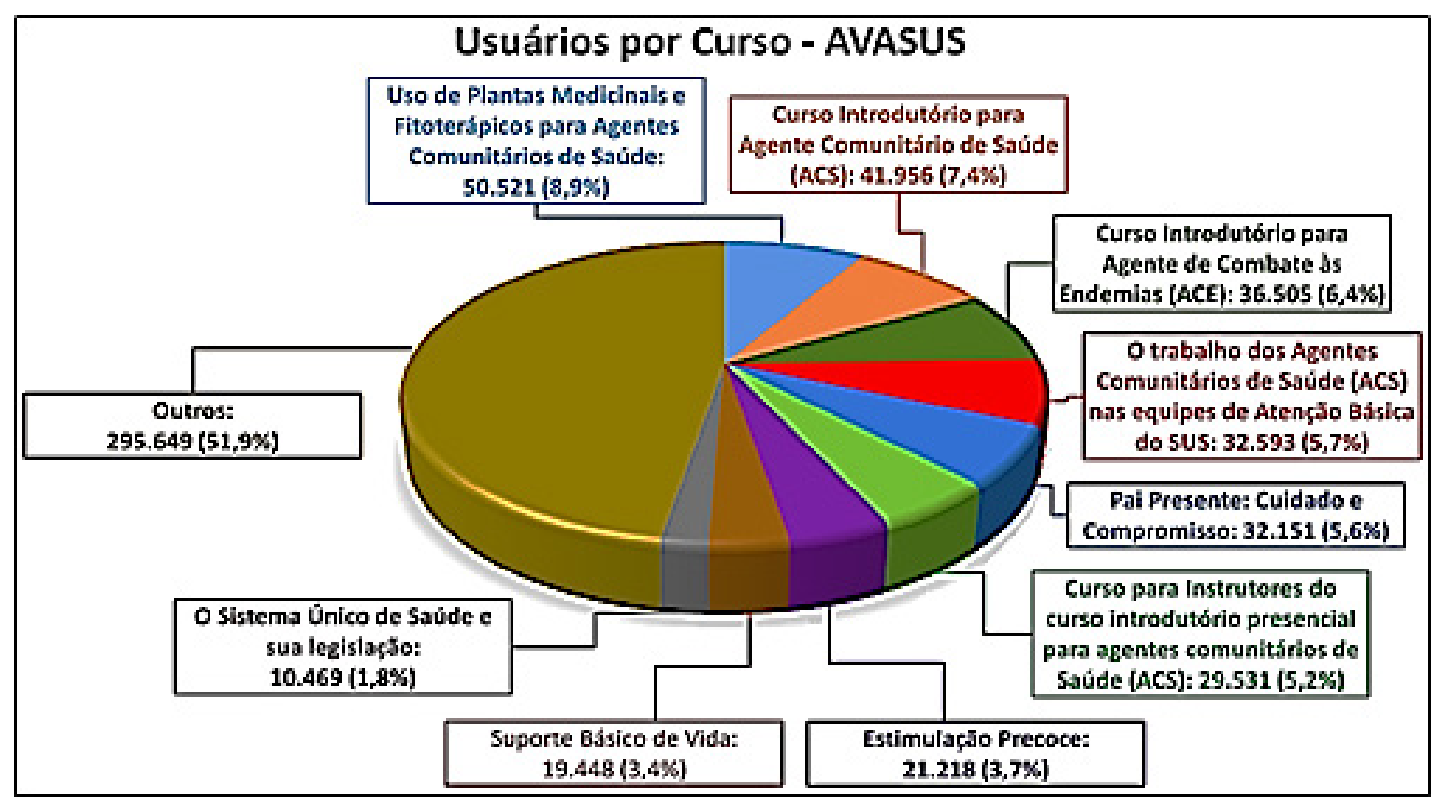

Figura 3 - Gráfico com o resumo do número de usuários do AVASUS.

Fonte: Autoria própria (2018).

$\mathrm{Na}$ Tabela 1, apresentam-se características dos conteudistas acerca da experiência no ensino com atuação na produção de material didático, possibilitando mais conhecimento desse público e melhor entendimento para formulação de hipóteses. Um ponto importante a ser observado é que $42,9 \%$ dos profissionais pesquisados já produziram material didático, porém, apenas para educação presencial e 38,1\% nunca realizaram trabalho relacionado. Isso indica que $81 \%$ dos conteudistas deste estudo não tiveram experiência anterior na produção de material didático. Com esses dados, evidencia-se que, diante da pouca experiência, faz-se necessária a criação de estratégias 
eficazes na preparação dos profissionais da saúde que estão se propondo a elaborar material didático para a educação mediada por tecnologia aplicada à saúde.

Tabela 1: Características gerais dos conteudistas.

\begin{tabular}{|l|l|}
\hline \multicolumn{2}{|c|}{ CARACTERÍSTICAS GERAIS } \\
\hline Experiência apenas no ensino presencial & $\mathbf{6 1 , 9 \%}$ \\
\hline Experiência com o ensino presencial e o EaD & $\mathbf{2 3 , 8 \%}$ \\
\hline Não tinham experiência no ensino & $\mathbf{1 4 , 3 \%}$ \\
\hline Entre 6 e 10 anos de experiência lecionando & $\mathbf{3 8 , 1 \%}$ \\
\hline Acima de 21 anos de experiência lecionando & $\mathbf{1 9 \%}$ \\
\hline Já produziu material didático para educação presencial & $\mathbf{4 2 , 9 \%}$ \\
\hline Já produziu material didático para EaD & $\mathbf{1 9 \%}$ \\
\hline Nunca haviam realizado trabalho voltado para elaboração de material didático & $\mathbf{3 8 , 1 \%}$ \\
\hline
\end{tabular}

Para ampliar o entendimento sobre as carências dos conteudistas, a Figura 4 mostra um dos questionamentos da abordagem realizada, em que 71,4\% do conteudistas que participaram desta pesquisa consideram que o grau de dificuldade na produção do módulo é médio, ou seja, grau 3 levando-se em consideração que foi usada uma escala de mensuração de 1 a 4.

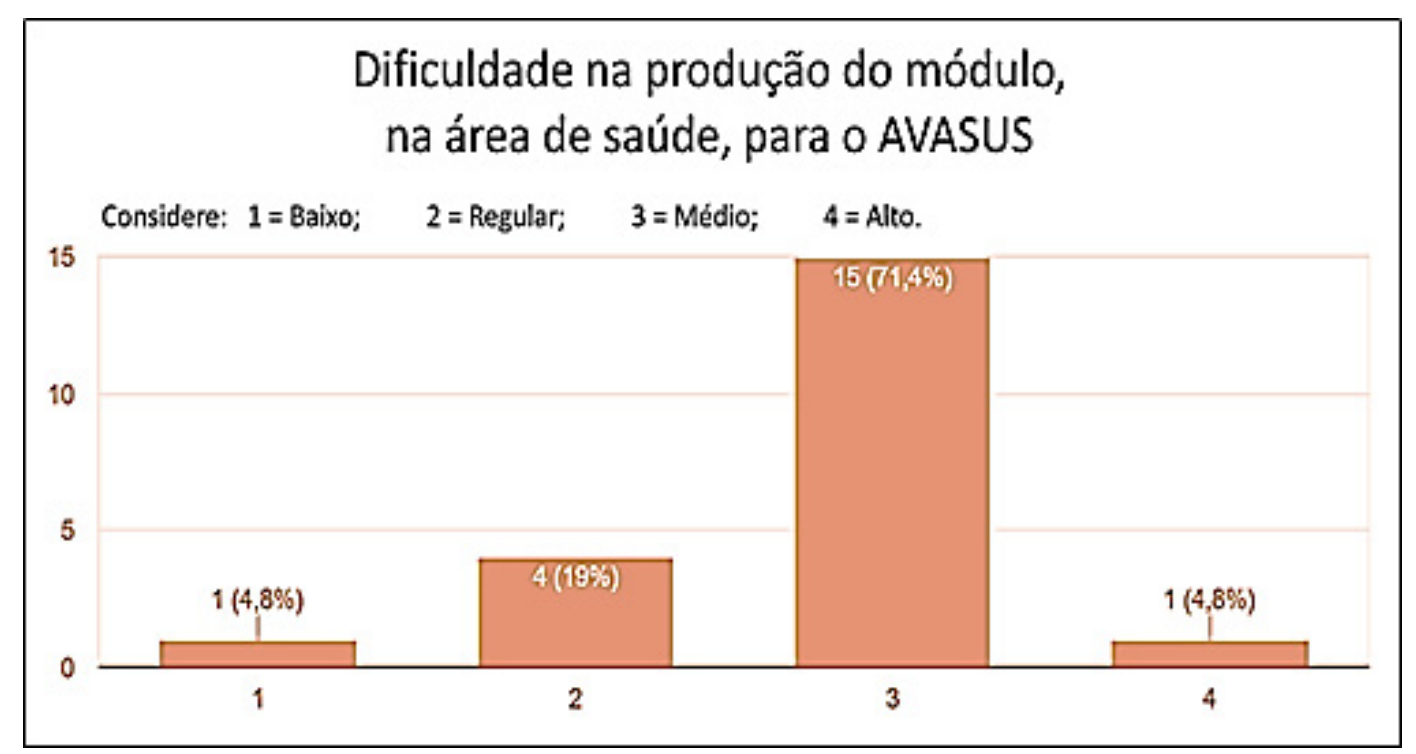

Figura 4 - Gráfico da dificuldade na elaboração do módulo.

Fonte: Autoria própria (2018).

Diante desses resultados, a Figura 5 possibilita uma melhor compreensão do fator que mais dificultava o trabalho dos conteudistas. Por meio das indagações realizadas, verificou-se, nas respostas, que 52,4\% julgam o uso da linguagem dialógica e de metodologias não tradicionais como motivo de dificuldade com grau 3 na mesma escala de 1 a 4. 


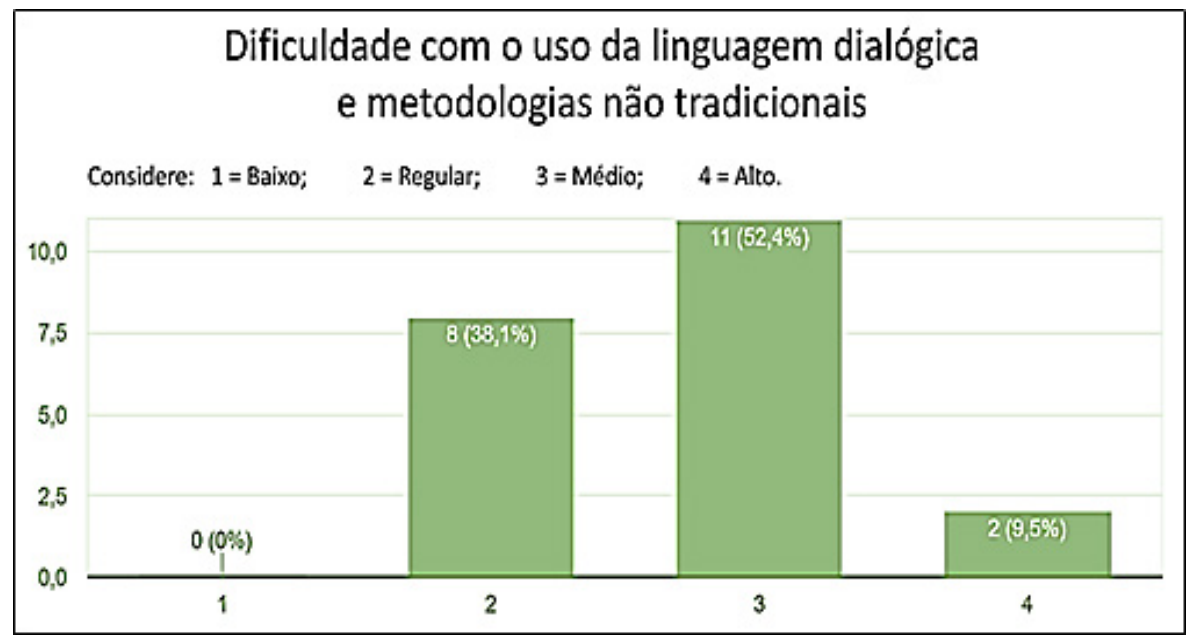

Figura 5 - Gráfico do uso da linguagem dialógica e metodologias não tradicionais. Fonte: Autoria própria (2018).

Na Figura 6, destacam-se questões discutidas com o grupo focal, formado por conteudistas em vários segmentos de produção e o que se apresenta como principal dificuldade na elaboração dos módulos é a construção de recursos audiovisuais. Já na entrevista individual, realizada com conteudista que já havia finalizado o módulo, fortalece-se a hipótese de que a linguagem dialógica na produção de material didático caracteriza-se como implicação árdua no desenvolvimento do produto, reforçando-se a necessidade de ser criados meios para auxiliar esse profissional que tem imensa responsabilidade em produzir conteúdo para educação mediada por tecnologia aplicada à saúde.

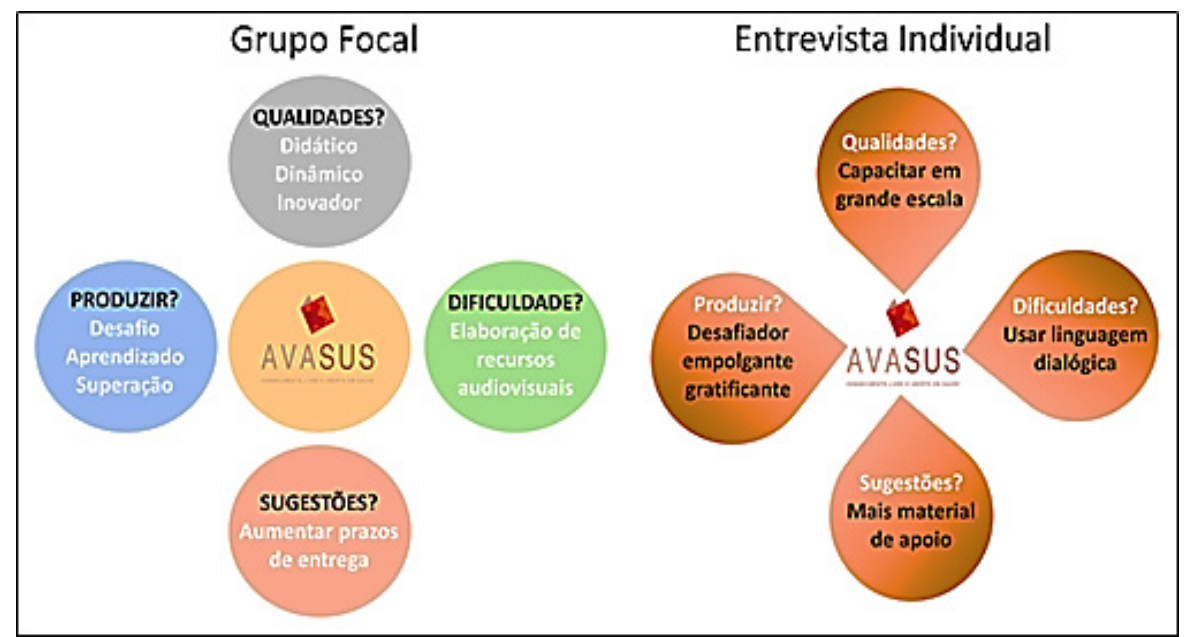

Figura 6 - Grupo focal e entrevista individual.

Fonte: Autoria própria (2018).

No Quadro 1, apresentam-se considerações a partir do ponto de vista de mais dois atores do processo, o coordenador de programa e, finalmente, o servidor ligado à produção dos módulos, visando à obtenção de um levantamento dos diversos aspectos relacionados ao AVASUS. Mais uma vez, elucida-se a dialogicidade como fator a ser dado ênfase na preparação dos conteudistas, sendo esta fundamental e indispensável à produção de material didático de qualidade, no contexto da educação a distância. 
Quadro 1 - Resumo das entrevistas individuais: coordenador e servidor.

\begin{tabular}{|c|c|c|}
\hline PONTOS DE DISCUSSÃO & COORDENADOR DE PROGRAMA & SERVIDOR LIGADO AO AVASUS \\
\hline O AVASUS & $\begin{array}{l}\text { Plataforma atemporal, material com } \\
\text { qualidade excelente. }\end{array}$ & $\begin{array}{l}\text { Conteúdo focado nas necessidades dos } \\
\text { serviços de saúde. }\end{array}$ \\
\hline Dificuldades dos conteudistas & $\begin{array}{l}\text { Com a linguagem dialógica e com } \\
\text { recursos audiovisuais. }\end{array}$ & Escrever pensando no público-alvo. \\
\hline Possíveis melhorias & Formação prática para conteudistas. & $\begin{array}{l}\text { Mais integração entre todas as etapas } \\
\text { do processo. }\end{array}$ \\
\hline Apoio aos conteudistas & $\begin{array}{l}\text { Suporte com reuniões e } \\
\text { acompanhamento. }\end{array}$ & $\begin{array}{l}\text { Desde a instrução até um apoio } \\
\text { psicológico. }\end{array}$ \\
\hline Resumindo o processo & Processo de melhoria. & $\begin{array}{l}\text { Construção de afetividade com o } \\
\text { processo. }\end{array}$ \\
\hline
\end{tabular}

Fonte: Autoria própria (2018).

Portanto, percebe-se que a dialogicidade, como intrínseca ao processo, implica a agilidade e a flexibilidade, a orientação e a construção do conhecimento, a divergência e a convergência de ideias, refletindo tanto no ensino como na aprendizagem. Ademais, a inovação na maneira de ensinar e de aprender pode refletir na transformação das práticas cotidianas a partir do envolvimento dos profissionais, possibilitando que eles tenham um papel ativo na construção do conhecimento, sendo sujeitos produtores de sua própria aprendizagem significativa.

\section{CONSIDERAÇÕES FINAIS}

As instituições ligadas ao sistema de saúde brasileiro têm como finalidade prestar um serviço de qualidade à população. Para isso, são orientadas estrategicamente a capacitar lideranças e profissionais, proporcionando a melhoria dos serviços por meio da construção de novos conhecimentos, da motivação, da potencialização dos resultados e do desenvolvimento profissional.

Nesse sentido, os AVAs mostram-se como promissores perante o desenvolvimento de competências profissionais, com flexibilidade e temporalidade, como também para a inovação da prática pedagógica em saúde, possibilitando que gestores tracem meios significativos e satisfatórios de ensinar e de aprender. Dessa maneira, os demais profissionais do SUS podem repensar suas práticas, internalizando suas responsabilidades, atribuições inerentes a seus cargos, funções ocupadas e os desafios do cotidiano na busca por novos conhecimentos. O AVASUS, como potencial ferramenta para aliar formação de qualidade e em larga escala para esses profissionais, apresenta-se como ambiente virtual de aprendizagem didático, com conteúdo criativo, dinâmico, compacto e inovador, preocupando-se com a acessibilidade, com a linguagem dialógica e sendo diverso em recursos, além de ter credibilidade institucional.

Com este estudo, elucida-se, primeiro, a importância da mediação tecnológica na formação humana. Segundo, demonstra-se que uma das principais dificuldades enfrentadas por conteudistas na produção de material didático para educação mediada por tecnologia é o uso da linguagem dialógica. Terceiro, evidencia-se a importância de uma solução pedagógica eficaz para subvencionar os conteudistas, oferecendo-lhes mais aporte à produção de material didático com dialogicidade e qualidade a ser pensada e desenvolvida em trabalhos futuros. 


\section{REFERÊNCIAS}

ANTUNES, M. C. S. et al. Educação dos profissionais da saúde através da EAD: um olhar no Rio Grande do Norte. Revista brasileira de educação profissional tecnológica, v. 1, n. 6, 2013.

AVASUS. Ambiente Virtual de Aprendizagem do Sistema Único de Saúde. Transparência. Disponível em: https://avasus.ufrn.br/local/ avasplugin/dashboard/transparencia.php. Acesso em: 21 set. 2018.

BIZAGI. Digital Business Platform. Produtos. Modelador. Disponível em: https://www.bizagi.com/pt/produtos/bpm-suite/modeler. Acesso em: 12 jan. 2019.

BRASIL. Presidência da República. Lei 8.080, de 19 de setembro de 1990. Dispõe sobre as condições para a promoção, proteção e recuperação da saúde, a organização e o funcionamento dos serviços correspondentes e dá outras providências. Brasília, DF: Presidência da República, 1990.

BRASIL. Ministério da Saúde. Portaria GM/MS n. 1996, de 20 de agosto de 2007. Dispõe sobre as diretrizes para a implementação da Política Nacional de Educação Permanente em Saúde e dá outras providências. Brasília, DF: Ministério da Saúde, 2007.

BRASIL. Ministério da Saúde. Portaria GM/MS n. 278, de 27 de fevereiro de 2014. Institui diretrizes para implementação da Política de Educação Permanente em Saúde, no âmbito do Ministério da Saúde (MS). Brasília, DF: Ministério da Saúde, 2014.

COSTA, I. K. F. et al. Utilização da tecnologia no ensino a distância em suporte básico de vida. Revista Brasileira de Inovação Tecnológica em Saúde, v. 8, n. 2, 2018.

CRESWELL, J. W. Projeto de Pesquisa: métodos qualitativo, quantitativo e misto. Porto Alegre: Artmed Bookman, 2007.

DATASUS. Departamento de Informática do Sistema Único de Saúde. O DATASUS. Disponível em: http://datasus.saude.gov.br/ datasus. Acesso em: 14 jun. 2018.

FIGUEIREDO, A. M. et al. Curso Autoinstrucional em Telessaúde: uma visão geral. Revista Brasileira de Inovação Tecnológica em Saúde, v. 5, n. 4, 2016.

FILATRO, A. Design instrucional na prática. São Paulo: Pearson Prentice Hall, 2008. 
FILHO, J. A. P. et al. Indicadores: gestão e análise de dados no sistema de educação permanente em saúde. In: CONFERÊNCIA INTERNACIONAL DE INOVAÇÃO TECNOLÓGICA EM SAÚDE. 1., 2018. Anais [...]. Natal: SEDIS-UFRN, 2018.

FONSECA, J. J. S. Metodologia da pesquisa científica. Fortaleza: UEC, 2002.

FREIRE, P. Pedagogia da Autonomia: saberes necessários à prática educativa. 41. reimpr. São Paulo: Paz e Terra, 2010. (Coleção Leitura).

GIDDENS, A. Sociologia. 6. ed. Porto Alegre: Artmed, 2012.

LAASER, W. (org.) Manual de criação e elaboração de materiais para a educação a distância. Brasília: Universidade de Brasília, 1997.

MINAYO, M. C. S. O desafio do conhecimento científico: pesquisa qualitativa em saúde. 2. ed. São Paulo/Rio de Janeiro: HucitecAbrasco, 1993.

OLIVEIRA, C. A. P. et al. Educação permanente em saúde: novas necessidades e perspectivas de formação, utilizando as TICs para aplicar estratégias pedagógicas inovadoras. In: ALVES, R. L. S. et al. Gestão de recursos humanos em saúde mediada por tecnologia: seguindo a trilha da inovação. Natal: EDUFRN, 2017.

OMG. Object Management Group. 2011. Business Process Model and Notation (BPMN). Version 2.0. Disponível em: http://www.omg. org/spec/BPMN/2.0/PDF. Acesso em: 11 jan. 2019.

ONU BR. Nações Unidas no Brasil. A Agenda 2030. Disponível em: https://nacoesunidas.org/pos2015/ods4. Acesso em: 5 set. 2018.

UNA-SUS. Universidade Aberta do Sistema Único de Saúde.

Institucional. Disponível em: https://www.unasus.gov.br/institucional. Acesso em: 18 jun. 2018.

UNIVERSUS. Ambiente Virtual de Ensino a Distância e Trabalho Colaborativo do Ministério da Saúde. Página Inicial. Disponível em: http://universus.datasus.gov.br. Acesso em: 15 jun. 2018.

VERGARA, Sylvia Constant. Projetos e relatórios de pesquisa em administração. 5. ed. São Paulo: Atlas, 2004. 